\title{
ChemComm
}

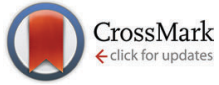

Cite this: Chem. Commun., 2015, 51, 7376

Received 5th February 2015

Accepted 24th March 2015

DOI: $10.1039 / \mathrm{c5cc01103e}$

www.rsc.org/chemcomm

\section{Perovskite solar cells prepared by flash evaporation}

\author{
Giulia Longo, Lidón Gil-Escrig, Maarten J. Degen, Michele Sessolo and \\ Henk J. Bolink*
}

\begin{abstract}
A simple vacuum deposition method for the preparation of high quality hybrid organic-inorganic methylammonium lead iodide perovskite thin films is reported. When sandwiched in between organic charge transporting layers, such films lead to solar cells with a power conversion efficiency of $12.2 \%$.
\end{abstract}

Organic-inorganic (hybrid) halide perovskites consisting of aliphatic or aromatic ammonium cations and divalent metals have been the focus of several studies due to their interesting optoelectronic properties, high charge mobility and ease of deposition even through solution-based methods. ${ }^{1,2}$ More recently, three dimensional hybrid perovskites have been successfully employed as light harvesters in thin film solar cells. ${ }^{3,4}$ Thanks to a large scientific effort by a number of research groups, the device performance has seen a spectacular rise and, in only five years, a record power conversion efficiency (PCE) as high as $20.1 \%$ has been reported..$^{5-14}$ Early studies focused mainly on the optimization of the solar cell architecture through interface engineering, i.e. choice of proper hole transport materials (HTMs), ${ }^{4,9,15,16}$ and electron transport materials (ETMs). ${ }^{3,8,12,17,18}$ Most recent investigations, however, have demonstrated that the control over the perovskite crystallization plays a main role in the achievement of high PCE devices. ${ }^{19,20}$ Homogeneous perovskite films with large crystal size are desirable since they would allow to increase the layer thickness, thus increasing the sunlight absorption, without hindering the charge transport and collection. Many different strategies have been proposed so far for the solution-processing of hybrid perovskites. ${ }^{21-26}$ Besides the deeper understanding on the structure-properties relation in methylammonium lead halide perovskite cells, these studies also highlighted the complexity and interplay of parameters involved in the solution deposition of such materials. Taking into account that perovskite solar cells are potential candidate for complementing

Instituto de Ciencia Molecular, Universidad de Valencia, c/Catedrático J. Beltrán, 2, 46980 Paterna, Spain. E-mail: henk.bolink@uv.es; Fax: +34-963543273; Tel: $+34-963544416$ silicon or copper indium gallium selenide (CIGS) cells in tandem devices, the development of a reliable and thin-film compatible deposition technique is a primary task. Within this perspective, dual source vapour deposition has been proposed as an attractive alternative in the preparation of $\mathrm{CH}_{3} \mathrm{NH}_{3} \mathrm{PbI}_{3}$ thin films for photovoltaics. ${ }^{7,12}$ Perovskites layers were obtained by simultaneous controlled co-evaporation of the lead halide (either $\mathrm{PbCl}_{2}$ or $\mathrm{PbI}_{2}$ ) and the methylammonium iodide $\mathrm{CH}_{3} \mathrm{NH}_{3} \mathrm{I}$ (MAI) in high vacuum chambers. Such vapourdeposited films are very flat and homogeneous and, when employed in solar cells architecture, lead to PCEs as high as $16.5 \%{ }^{27}$ Co-evaporation enables a fine control over the stoichiometry and thickness of the perovskite films, and takes advantage of the intrinsic high purity of sublimated compounds. Moreover, the technique allows for the preparation of multi-layer stacks, and is fully compatible with standard semiconductor processing. On the other side, the process is relatively time-consuming and it requires accurate periodical calibrations to properly control the deposition rate and precursors ratio. An alternative physical method for the deposition of compound semiconductors is flash evaporation..$^{28,29}$ The material to be deposited is placed on a metal heater and brought to vacuum, and then a large current is passed through the heater causing the material to rapidly evaporate and condense onto a substrate. Layered, 2D perovskite metal halide doped with aliphatic or aromatic ammonium cations were deposited with this method, resulting in optically active, polycrystalline thin films. ${ }^{30}$ The desired hybrid film is formed at temperatures high enough for the inorganic compound to evaporate, without causing the decomposition of the organic component. $^{31}$

In this communication, we report the flash evaporation of 3D organic-inorganic hybrid perovskites and their use in efficient, planar photovoltaic devices. We show that uniform and smooth polycrystalline $\mathrm{CH}_{3} \mathrm{NH}_{3} \mathrm{PbI}_{3}$ thin films of the desired thickness can be obtained by careful tuning of the deposition parameters. The as-deposited material was characterized by optical and morphological methods, revealing a high 
degree of homogeneity as well as a low surface roughness, which is desirable for its implementation into optoelectronic devices. The photovoltaic properties of flash evaporated $\mathrm{CH}_{3} \mathrm{NH}_{3} \mathrm{PbI}_{3}$ thin films were evaluated in planar heterojunction solar cells employing organic charge transport layers. High PCE up to $12 \%$ were obtained, demonstrating the potential of flash evaporation as an alternative method for the production of efficient perovskite solar cells. While the flash evaporation technique allows for the deposition of hybrid perovskite films even from their powders as the precursor, we found that a better control over the thickness and homogeneity of the final layer is obtained if the metal heater is coated with the material to be deposited.

The MAI was synthetized according to a previously published method ${ }^{32}$ and dried at $60{ }^{\circ} \mathrm{C}$ in vacuum for 24 hours. A $50 \mathrm{wt} \%$ perovskite precursor solution is prepared by dissolving $\mathrm{PbI}_{2}$ (Sigma Aldrich) and MAI in DMF, with a molar ratio $\mathrm{PbI}_{2}$ : MAI of about $1: 3$. The solution is subsequently deposited onto the metal heater (a tantalum foil of $70 \times 15 \times$ $0.05 \mathrm{~mm}$ ) by meniscus coating (Fig. 1a). ${ }^{33}$ The layer is created by placing $80 \mu \mathrm{l}$ of precursor solution under the metal blade (1.2 $\mathrm{mm}$ high) and by spreading it over the tantalum foil at a speed of $80 \mathrm{~mm} \mathrm{~s}^{-1}$. During deposition the foil is heated at $80{ }^{\circ} \mathrm{C}$ and once the perovskite layer forms (i.e. the layer turns from yellow to dark brown, Fig. 1b), it is heated at $125{ }^{\circ} \mathrm{C}$ for 5 minutes in order to remove the excess solvent. The tantalum foil is subsequently transferred into a high vacuum chamber and clamped in between two electrodes connected to a high current source (Fig. 1c). The substrates to be coated are placed on a sample holder mounted at a vertical distance of $10 \mathrm{~cm}$ from the evaporation source. After establishing a stationary vacuum of approximately 0.1 mbar, a large current (approximately $30 \mathrm{~A}$ ) is passed through the tantalum foil, causing the complete and virtually instantaneous evaporation of the $\mathrm{CH}_{3} \mathrm{NH}_{3} \mathrm{PbI}_{3}$. The resulting film thickness is controlled by the amount of perovskite initially deposited on the metal heater. The grazing incident X-ray diffraction (GIXRD) pattern of an

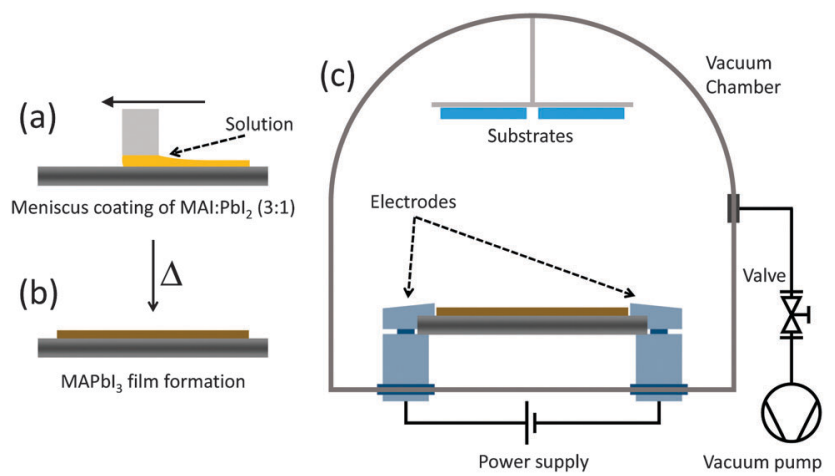

Fig. 1 Process flow for the deposition of hybrid organic-inorganic perovskite thin films via flash evaporation. (a) The precursor solution is spread onto a tantalum foil via meniscus coating and (b) annealed to obtain a polycrystalline $\mathrm{CH}_{3} \mathrm{NH}_{3} \mathrm{Pbl}$ film. The coated tantalum sheet is then transferred to a vacuum chamber (c) where the hybrid perovskite is evaporated onto the desired substrate.
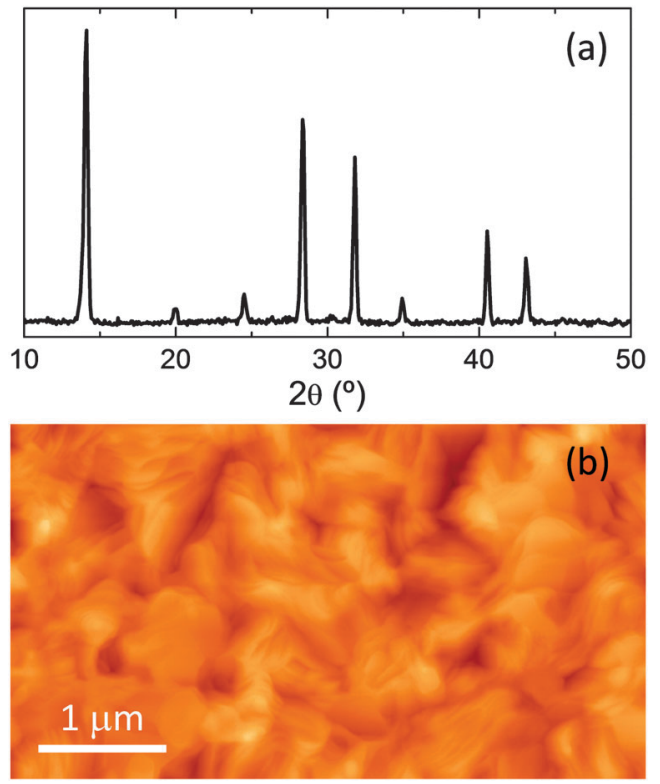

Fig. 2 (a) GIXRD pattern and (b) AFM topography of a $\mathrm{CH}_{3} \mathrm{NH}_{3} \mathrm{Pbl}_{3}$ thin film deposited by flash evaporation.

as-deposited $200 \mathrm{~nm}$ thick film is reported in Fig. 2a. The spectrum suggests a high degree of crystallinity, with the peaks at $14.1^{\circ}, 28.4^{\circ}$ and $31.8^{\circ}$ confirming the formation of the tetragonal structure of the $\mathrm{MAPbI}_{3}$ perovskite. The surface topography of the film was also investigated by atomic force microscopy (AFM, Fig. 2b). The film shows homogenous aggregation and is relatively flat, with a root mean square (RMS) roughness, calculated over an area of $25 \mu \mathrm{m}^{2}$, of $17.6 \mathrm{~nm}$. These data demonstrate that a 3D hybrid organic-inorganic perovskite can be evaporated and reassembled onto a desired substrate with a high degree of crystallinity and homogeneous morphology. These characteristics are of particular interest for optoelectronic applications such as thin film photovoltaic devices. Single junction solar cell were prepared by integration of the perovskite films in a multilayer stack of organic semiconducting layers. Indium tin oxide (ITO) coated glass slides were used as bottom transparent electrode.

An $80 \mathrm{~nm}$ thick of poly(3,4-ethylenedioxythiophene) doped with poly(styrenesulfonate) (PEDOT:PSS, Heraeus Clevios ${ }^{\mathrm{TM}} \mathrm{P}$ VP AI 4083) was spin-coated onto the ITO and used as the hole injection layer (HIL). After annealing it at $150{ }^{\circ} \mathrm{C}$ for 15 minutes, a $20 \mathrm{~nm}$ thick poly( $N, N^{\prime}$-bis(4-butylphenyl)- $N, N^{\prime}$-bis(phenyl)benzidine) (polyTPD) HTL was deposited on top from chlorobenzene (1 wt\%) and annealed at $180{ }^{\circ} \mathrm{C}$ for $30 \mathrm{~s}$. The polymer stack was subsequently transferred to the vacuum chamber and a $200 \mathrm{~nm}$ thick film of $\mathrm{MAPbI}_{3}$ perovskite was deposited by flash evaporation. The stack was completed by spin-coating an $80 \mathrm{~nm}$ thick $(6,6)$-phenyl $\mathrm{C}_{61}$-butyric acid methyl ester (PCBM) thin film and with the thermal vacuum deposition of a bilayer cathode composed of $\mathrm{Ba}$ and $\mathrm{Ag}$ (10 and $100 \mathrm{~nm}$, respectively). The device characterization was performed in a nitrogen glove box, using a mini-sun simulator designed by ECN and calibrated with a Si reference cell. The device EQE as well as the perovskite 

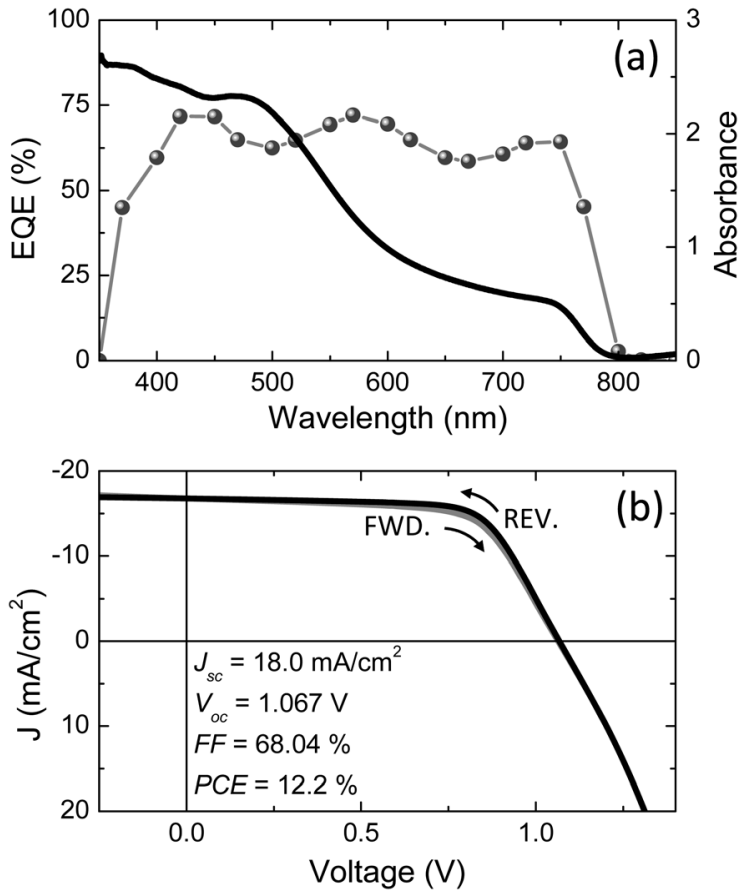

Fig. 3 (a) EQE (symbols) and optical absorption (line) in the UV-visible region for a planar perovskite solar cell and its active layer, respectively, deposited by flash evaporation. (b) $J-V$ curve in forward (FWD.) and reverse (REV.) bias for a device under illumination with the structure ITO/PEDOT:PSS/polyTPD/MAPb| $/ 3 / \mathrm{PCBM} / \mathrm{Ba} / \mathrm{Ag}$. The scan rate in both bias direction was $0.1 \mathrm{~V} \mathrm{~s}^{-1}$

film UV-visible absorption spectrum are reported in Fig. 3a. The optical absorption shows the typical profile of the $\mathrm{MAPbI}_{3}$ perovskite, with a broad absorption over the whole visible spectrum and onset at about $800 \mathrm{~nm}$, corresponding to an optical band gap of $1.55 \mathrm{eV}$. The EQE rises at the same wavelength, reaching a maximum value of $73 \%$ in the green $(570 \mathrm{~nm})$ and in the blue (420$450 \mathrm{~nm})$ region of the spectrum. The current density-voltage $(J-V)$ characteristic of the solar cell is reported in Fig. $3 \mathrm{~b}$. The $J-V$ curve is almost independent on the scan direction, in contrary to what often observed for solution-processed perovskite devices. The shortcircuit current density $\left(J_{\mathrm{SC}}\right)$, open-circuit voltage $\left(V_{\mathrm{OC}}\right)$ and fill factor (FF) for a typical device, are $18.0 \mathrm{~mA} \mathrm{~cm}{ }^{-2}, 1.07 \mathrm{~V}$ and $68 \%$, respectively, leading to a remarkable power conversion efficiency of $12.2 \%$. This result is of great importance for the future development of photovoltaic devices based on hybrid organic-inorganic perovskite materials, especially in view of their integration with existing thin film photovoltaic technologies. The deposition process is scalable, additive and extremely fast (in the order of few seconds), which is desirable for the implementation of this materials in industrial applications.

In summary, 3D methylammonium lead iodide perovskites have been prepared by flash evaporation. Homogeneous and highly crystalline thin films can be obtained with unique control over the material composition and film thickness. The as-deposited films have been tested in planar solar cells employing organic charge transport layers, demonstrating power conversion efficiencies exceeding 12\%. This method allows for a straight-forward preparation of multi-layer structures of different organic-inorganic materials, which are foreseen as the big challenge in hybrid perovskite devices. Moreover, the simplicity of the process is particularly suited for the preparation of tandem solar cells, where the perovskite device could be used as a top transparent device in silicon or CIGS photovoltaic modules.

\section{Notes and references}

1 C. R. Kagan, D. B. Mitzi and C. D. Dimitrakopoulos, Science, 1999, 286, 945-947.

2 D. B. Mitzi, C. A. Feild, W. T. A. Harrison and A. M. Guloy, Nature, 1994, 369, 467-469.

3 A. Kojima, K. Teshima, Y. Shirai and T. Miyasaka, J. Am. Chem. Soc., 2009, 131, 6050-6051.

4 M. M. Lee, J. Teuscher, T. Miyasaka, T. N. Murakami and H. J. Snaith, Science, 2012, 338, 643-647.

5 H. J. Snaith, J. Phys. Chem. Lett., 2013, 4, 3623-3630.

6 N. G. Park, J. Phys. Chem. Lett., 2013, 4, 2423-2429.

7 M. Liu, M. B. Johnston and H. J. Snaith, Nature, 2013, 501, 395-398.

8 H. Zhou, Q. Chen, G. Li, S. Luo, T. B. Song, H. S. Duan, Z. Hong, J. You, Y. Liu and Y. Yang, Science, 2014, 345, 542-546.

9 P. Gao, M. Grätzel and M. K. Nazeeruddin, Energy Environ. Sci., 2014, 7, 2448-2463.

10 S. Kazim, M. K. Nazeeruddin, M. Grätzel and S. Ahmad, Angew. Chem., Int. Ed., 2014, 53, 2812-2824.

11 P. P. Boix, K. Nonomura, N. Mathews and S. G. Mhaisalkar, Mater. Today, 2014, 17, 16-23.

12 O. Malinkiewicz, A. Yella, Y. H. Lee, G. M. Espallargas, M. Graetzel, M. K. Nazeeruddin and H. J. Bolink, Nat. Photonics, 2014, 8, 128-132.

13 M. Gratzel, Nat. Mater., 2014, 13, 838-842.

14 M. A. Green, K. Emery, Y. Hishikawa, W. Warta and E. D. Dunlop, Prog. Photovolt.: Res. Appl., 2015, 23, 1-9.

15 P. Qin, S. Tanaka, S. Ito, N. Tetreault, K. Manabe, H. Nishino, M. K. Nazeeruddin and M. Grätzel, Nat. Commun., 2014, 5, 3834.

16 J. Y. Jeng, K. C. Chen, T. Y. Chiang, P. Y. Lin, T. D. Tsai, Y. C. Chang, T. F. Guo, P. Chen, T. C. Wen and Y. J. Hsu, Adv. Mater., 2014, 26, 4107-4113.

17 A. Mei, X. Li, L. Liu, Z. Ku, T. Liu, Y. Rong, M. Xu, M. Hu, J. Chen, Y. Yang, M. Grätzel and H. Han, Science, 2014, 345, 295-298.

18 J. Y. Jeng, Y. F. Chiang, M. H. Lee, S. R. Peng, T. F. Guo, P. Chen and T. C. Wen, Adv. Mater., 2013, 25, 3727-3732.

19 W. Nie, H. Tsai, R. Asadpour, J.-C. Blancon, A. J. Neukirch, G. Gupta, J. J. Crochet, M. Chhowalla, S. Tretiak, M. A. Alam, H.-L. Wang and A. D. Mohite, Science, 2015, 347, 522-525.

20 D. Shi, V. Adinolfi, R. Comin, M. Yuan, E. Alarousu, A. Buin, Y. Chen, S. Hoogland, A. Rothenberger, K. Katsiev, Y. Losovyj, X. Zhang, P. A. Dowben, O. F. Mohammed, E. H. Sargent and O. M. Bakr, Science, 2015, 347, 519-522.

21 J. Burschka, N. Pellet, S. J. Moon, R. Humphry-Baker, P. Gao, M. K. Nazeeruddin and M. Grätzel, Nature, 2013, 499, 316-319.

22 Q. Chen, H. Zhou, Z. Hong, S. Luo, H. S. Duan, H. H. Wang, Y. Liu, G. Li and Y. Yang, J. Am. Chem. Soc., 2014, 136, 622-625.

23 A. Dualeh, N. Tétreault, T. Moehl, P. Gao, M. K. Nazeeruddin and M. Grätzel, Adv. Funct. Mater., 2014, 24, 3250-3258.

24 G. E. Eperon, V. M. Burlakov, P. Docampo, A. Goriely and H. J. Snaith, Adv. Funct. Mater., 2014, 24, 151-157.

25 Z. Xiao, Q. Dong, C. Bi, Y. Shao, Y. Yuan and J. Huang, Adv. Mater., 2014, 26, 6503-6509.

26 N. J. Jeon, J. H. Noh, Y. C. Kim, W. S. Yang, S. Ryu and S. I. Seok, Nat. Mater., 2014, 13, 897-903.

27 Q. Lin, A. Armin, R. C. R. Nagiri, P. L. Burn and P. Meredith, Nat. Photonics, 2015, 9, 106-112.

28 L. Harris and B. M. Siegel, J. Appl. Phys., 1948, 19, 739-741.

29 J. L. Richards, P. B. Hart and L. M. Gallone, J. Appl. Phys., 1963, 34, 3418-3420.

30 D. B. Mitzi, M. T. Prikas and K. Chondroudis, Chem. Mater., 1999, 11, 542-544.

31 K. Chondroudis, D. B. Mitzi and P. Brock, Chem. Mater., 1999, 12, 169-175.

32 L. Etgar, P. Gao, Z. Xue, Q. Peng, A. K. Chandiran, B. Liu, M. K. Nazeeruddin and M. Grätzel, J. Am. Chem. Soc., 2012, 134, 17396-17399.

33 C. S. Herrick, Ind. Eng. Chem. Prod. Res. Dev., 1980, 19, 314-316. 